journal homepage: http://chimie-biologie.ubm.ro/carpathian_journal/index.html

\title{
RESEARCH OF TECHNOLOGICAL PARAMETERS AND CRITERIA FOR EVALUATING DISTILLATE PRODUCTION FROM DRIED JERUSALEM ARTICHOKE
}

\author{
L.A. Oganesyants ${ }^{1}$, V.A. Peschanskaya ${ }^{1}$, L.N. Krikunova ${ }^{1}$, E.V. Dubinina ${ }^{1 *}$ \\ ${ }^{I}$ All-Russian Scientific Research Institute of the Brewing, Non-Alcoholic and Wine Industry - Branch of the \\ V.M. Gorbatov Federal Scientific Center of Food Systems of RAS, 7, Rossolimo St., Moscow, Russia, 119021 \\ *elena-vd@yandex.ru
}

https://doi.org/10.34302/crpjfst/2019.11.2.15

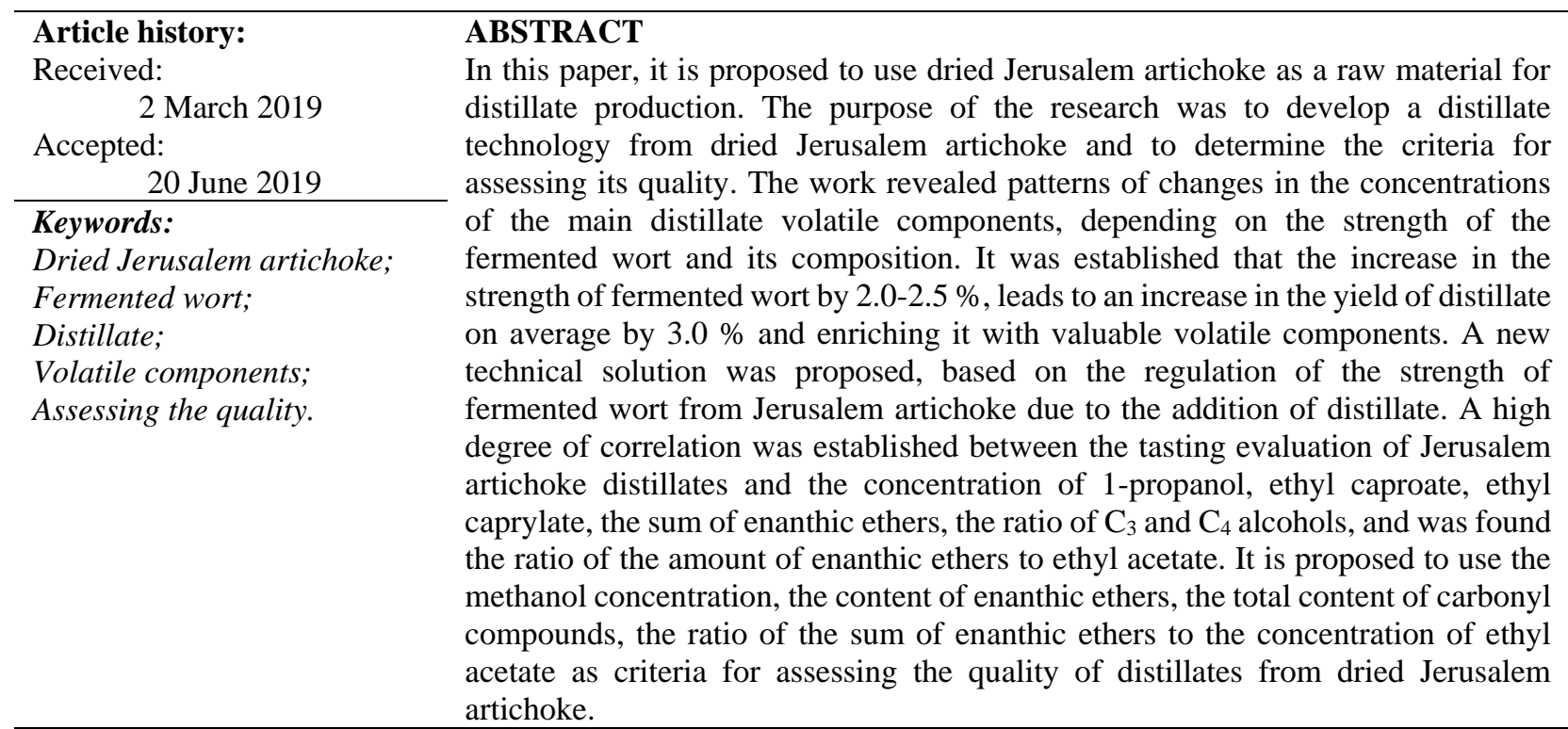

\section{Introduction}

The unflagging interest in the Jerusalem artichoke use as a raw material in the food industry in the Russian Federation and abroad has been associated with its unique biochemical composition for several decades. The main areas of researches in the field of application of this crop are developments aimed at producing inulin, a polymer of fructose, which is widely used in creating functional foods and dietary supplements (Bekers et al., 2008; Lisovoy et al., 2016; Barkhatova et al., 2015), use of Jerusalem artichoke prepared in various ways as an ingredient of food products (Yakovleva and Arsen'eva, 2012; Shazzo et al., 2013; Baranenko and Borisova, 2014) and pectin production (Toshkov et al., 2015). Known the developments of Russian and foreign experts in obtaining ethyl alcohol by rectification of fermented wort from Jerusalem artichoke (Nakamura et al., 1996; Ponomareva et al., 2009; Pornthap Thanonkeo et al., 2011).

This type of inulin-containing raw material can also be promising in the production of alcoholic drinks based on distillates. The climatic conditions of the Russian Federation make it possible to grow this crop in sufficient quantities for production. Interest in the use of Jerusalem artichoke in the wine industry is also due to its relatively low purchase price compared to fruit raw materials.

It is known, that the tubers of fresh Jerusalem artichoke are difficult to store as raw materials due to the characteristics of the covering tissues (Ilchenko and Patlasov, 2016). In order to increase its storage time, methods have been proposed earlier, involving 
the use of a controlled gaseous medium or lower temperatures (Khripko and Kozhukhova, 2003). However, these methods require the use of specialized expensive equipment. Therefore, the organization of year-round production of distillate from fresh Jerusalem artichoke tubers is not economically feasible. In this regard, German specialists use Jerusalem artichoke tubers to produce distillates exclusively as seasonal raw materials (Dürr et al., 2010).

As an alternative to fresh raw materials, was conducted research on the use of dried Jerusalem artichoke. The advantages of dried Jerusalem artichoke are possibility of yearround production, the high stability of its biochemical composition and microbiological purity, the partial depolymerization of the main carbohydrate components of the raw material and, consequently, an increase in their accessibility to enzymatic hydrolysis (Krikunova et al., 2016). The use of dried Jerusalem artichoke allows to simplify the technological process, eliminating the stage of washing and crushing.

Earlier, the main regularities of changes in the carbohydrate complex of dried Jerusalem artichoke in the preparation of the saccharified wort were identified and technological modes of preparation of raw materials for distillation were developed (Oganesyants et al., 2016). Was showed the advantages of using Fermiol alcohol yeast, as compared to the use of wine and brewing yeast, allowing to intensify the fermentation process, to get a wort with a maximum strength and a minimum content of acetaldehyde and methanol (Oganesyants et al., 2017).

The purpose of this work was to identify patterns of changes in the main volatile component concentrations of distillate from Jerusalem artichoke, depending on the strength of the fermented wort and its composition, to develop a new technological method, aimed at increasing the yield of distillate and improving its organoleptic characteristics.

\section{Materials and methods}

\subsection{Materials}

Dried Jerusalem artichoke from the tubers of the Skorospelka variety was obtained from
Topinambur LLC (Tver Region, Russian Federation). The method of dried Jerusalem artichoke production involves washing, sorting, inspection, calibration, cleaning, additional cleaning, cutting, blanching, drying and subsequent grinding (Golubev and Volkova, 1995). The biochemical composition of dried Jerusalem artichoke we studied previously (Krikunova et al., 2016).

Samples of fermented wort from dried Jerusalem artichoke, obtained by two-and onestage methods (control); wort samples prepared for distillation (experimental); distillate fractions, selected by strength and organoleptic characteristics; samples of distillate were used in this study.

\subsubsection{Obtaining a fermented wort}

The control sample $\mathrm{C} 1$ of fermented wort from dried Jerusalem artichoke was obtained according to the previously developed twostage method, namely:

- at the saccharified wort obtaining stage: hydronic module $1 \div 4.5$; enzymatic hydrolysis of raw materials polymers due to its own Jerusalem artichoke enzymes and microbial inulinases (3.0 units/g of inulin raw material) and proteases ( 0.01 units/g of protein raw material); the duration of hydrolysis is 3 hours at $50{ }^{\circ} \mathrm{C}$.

- at the saccharified wort fermentation stage: the use of dry Fermiol alcoholic yeast with an application rate of $100 \mathrm{mg} / 100 \mathrm{~g}$ of wort; fermentation at a temperature of $28-30{ }^{\circ} \mathrm{C}$ for 48 hours.

A control sample of $\mathrm{C} 2$ fermented wort from dried Jerusalem artichoke was obtained by a one-step method, including mixing the raw material with water at a water ratio of $1 \div 4.5$, acidifying the wort with $\mathrm{H}_{2} \mathrm{SO}_{4}$ solution to $\mathrm{pH} 4.5$; the use of microbial inulinase with a dosage of 4.0 units/g of inulin raw materials; the introduction of a fermentation activator; the use of Fermiol dry alcoholic yeast with an application rate of $100 \mathrm{mg} / 100 \mathrm{~g}$ of wort; fermentation at a temperature of $28-30{ }^{\circ} \mathrm{C}$ for 72 hours. At the same time, Vitamon Kombi (Erbsloeh, Germany), which is a mixture of pure ammonium phosphate and thiamine (vitamin $\mathrm{B}_{1}$ ), was used as a fermentation activator. 


\subsubsection{Experimental samples preparation}

The experimental samples of wort were prepared by introducing into the control samples a certain volume of distillate, obtained as a result of fractionated distillation of control samples previous batches. The amount of introduced distillate was determined on the basis of increasing the strength of the fermented wort by $1.0-4.0 \%$ by volume. The increase in the strength of samples S 1.1 and S 2.1 was $0.9-1.1 \%$ vol.; samples S 1.2 and S 2.2 - 1.9-2.1\% vol.; samples S 1.3 and S 2.3 - 2.9$3.1 \%$ vol.; samples S 1.4 and S $2.4-3.9-4.1 \%$ vol.

\subsubsection{Obtaining distillates}

Control and experimental samples of fermented wort were subjected to single fractionated distillation in a direct distillation unit with a strengthening column and a reflux condenser (Kothe Destillationstechnik, Germany). The temperature of the heating vapor was maintained from $102{ }^{\circ} \mathrm{C}$ (at the beginning of the distillation) to $105^{\circ} \mathrm{C}$ (at the end of the distillation). The heating vapor pressure in the distillation process was 0.2-0.5 $\mathrm{mPa}$. The selection of the head, average (heart) and tail fractions of the distillate was carried out according to organoleptic characteristics and strength.

\subsection{Methods}

The qualitative and quantitative composition of volatile components in the objects of research was determined by gas chromatography using a Thermo Trace GC
Ultra gas chromatograph (Thermo, USA) with a flame ionization detector (detection limit not more than $3 \cdot 10-12 \mathrm{~g} / \mathrm{s}$ ). Chromatography column HP FFAP: length $50 \mathrm{~m}$, internal diameter $0.32 \mathrm{~mm}$ with a membrane thickness of the stationary phase of $0.5 \mu \mathrm{m}$ (State Standart, 2016). In order to conduct a comparative analysis of the samples studied, the concentration of volatile components was expressed in $\mathrm{mg} / \mathrm{dm}^{3}$ of absolut alcohol $\left(\mathrm{mg} / \mathrm{dm}^{3}\right.$ of a.a.). For processing the research results, a statistical method for processing experimental data was used, during which the average values of measured values from 3-5 replications, the standard deviation and the confidence interval were determined (Borovikov, 2003; Grachev and Plaksin, 2005). Data in tables and figures are presented as averages of 3-5 dimensions. Mathematical planning and processing of experimental data was carried out using the methods of mathematical statistics using Excell 2007. The results of the correlation analysis were evaluated using tabular data on the critical values of the Pearson's code. For $\mathrm{p}=0.05$ with the number of degrees of freedom $18, r=0.44$.

\section{Results and discussions}

At the first stage of researches, was made a comparative assessment of volatile components composition and concentration in the control samples of fermented wort from dried Jerusalem artichoke, depending on the method of preparing raw materials for distillation (Table 1).

Table 1. The Main Control Samples Volatile Components Content of Fermented Wort from Dried Jerusalem Artichoke

\begin{tabular}{|c|c|c|}
\hline Volatile Components Content, $\mathrm{mg} / \mathrm{dm}^{3}$ of a.a. & C $1(7,31 \%$ vol. $)$ & C $2(7,58 \%$ vol. $)$ \\
\hline Acetaldehyde & 685 & 565 \\
\hline Ethyl acetate & 114 & 126 \\
\hline Methanol & 1181 & 971 \\
\hline Higher alcohols, including: & 2254 & 2191 \\
\hline - 1-propanol & 588 & 577 \\
\hline - isobutanol & 536 & 497 \\
\hline - isoamylol & 1130 & 1117 \\
\hline Enanthic ether & 28 & 22 \\
\hline Phenylethyl alcohol & 224 & 214 \\
\hline The sum of the components* & 4532 & 4146 \\
\hline
\end{tabular}

* In this table and in the subsequent when calculating the amount of volatile components, all identified impurities were taken into account, some of them are not included in the illustrative material. 
It was established that the method of obtaining fermented wort from dried Jerusalem artichoke affected on the total content of volatile components and the concentration of individual substances. In sample C 2, there was a decrease in acetaldehyde and methanol compared to sample C 1 by 17.5 and $17.8 \%$, respectively. The concentration of higher alcohols did not depend on the method of producing wort.

When comparing the data, presented in Table 1, and in a previously published paper (Krikunova et al., 2017), significant differences were found in the control samples of fermented wort from dried Jerusalem artichoke and samples of fermented wort from fresh tubers. Concentrations of higher alcohols and methanol in fermented wort from fresh raw materials, compared with the wort from dried Jerusalem artichoke, exceeded their values by $1.4-1.9$ and $4-5$ times, respectively. Therefore, it can be concluded that in terms of methanol content, an indicator characterizing the safety of alcoholic drinks, dried Jerusalem artichoke has significant advantages over fresh raw materials. At the same time, the marked lower content of higher alcohols, components that form the basis of the aroma of distillatebased alcoholic drinks, could adversely affect on the intensity of the aromatic characteristics of the finished product, which should be considered when developing a new distillate technology from dried Jerusalem artichoke.

In order to increase the mass concentration of aroma-forming components and the possibility of changing their volatility in the distillation process, wort prototypes (experimental samples) were obtained. They were prepared from control wort samples by adding distillate as described above.

The conditions for the transition of volatile components to distillate depend on many factors, including their solubility in ethyl alcohol and aqueous-alcoholic solutions of various concentrations, on their mutual miscibility and the type of distillate plant (Prado-Ramirez et al., 2005). Differences in the behavior of volatile components affect the organoleptic characteristics of individual fractions, selected during the distillation process and their yield (Claus and Berglund, 2005). On this basis, the addition of distillate to the fermented wort from dried Jerusalem artichoke could be a significant factor influencing the processes occurring during distillation. The content of the main volatile components of the experimental samples of wort is presented in Table 2.

Table 2. Volatile Composition of Experimental Wort Sampels

\begin{tabular}{|l|c|c|c|c|c|c|c|c|}
\hline $\begin{array}{l}\text { Volatile Components } \\
\text { Content, mg/dm }\end{array}$ of a.a. & S 1.1 & S 1.2 & S 1.3 & S 1.4 & S 2.1 & S 2.2 & S 2.3 & S 2.4 \\
\hline Acetaldehyde & 706 & 725 & 747 & 765 & 583 & 598 & 614 & 630 \\
\hline Ethyl acetate & 122 & 129 & 137 & 144 & 134 & 141 & 148 & 156 \\
\hline Methanol alcohols, & 1346 & 1508 & 1668 & 1825 & 1118 & 1262 & 1404 & 1544 \\
\hline $\begin{array}{l}\text { Higher } \\
\text { including: }\end{array}$ & 2506 & 3224 & 3536 & 2478 & 2752 & 3023 & 3291 \\
\hline - -propanol & 650 & 711 & 771 & 830 & 639 & 698 & 757 & 814 \\
\hline - isobutanol & 620 & 702 & 783 & 862 & 568 & 636 & 701 & 768 \\
\hline - isoamylol & 1313 & 1493 & 1670 & 1844 & 1271 & 1418 & 1565 & 1709 \\
\hline Enanthic ether & 34 & 40 & 46 & 51 & 29 & 35 & 42 & 48 \\
\hline $\begin{array}{l}\text { Phenylethyl alcohol } \\
\text { The sum of the } \\
\text { components }\end{array}$ & $\mathbf{5 0 6 5}$ & $\mathbf{5 5 8 9}$ & $\mathbf{6 1 0 5}$ & $\mathbf{6 6 1 2}$ & $\mathbf{4 6 5 2}$ & $\mathbf{5 0 7 3}$ & $\mathbf{5 5 2 5}$ & $\mathbf{6 1 7 1}$ \\
\hline
\end{tabular}

As can be seen from the obtained data, the increase in the strength of the fermented wort due to the introduction of a certain volume of distillate led to a change, as compared with the control, of both the total concentration and the content of individual volatile components. The total concentration of volatile components in the test samples increased on average by 10-30 $\%$. At the same time, the mass concentration of acetaldehyde, a component that gives rigidity to taste and aroma of distillates, increased, depending on the amount of distillate 
introduced, by $3.0-12.0 \%$. However, its relative content in the amount of volatile components decreased by $1.0-4.0 \%$. The absolute content of higher alcohols in the test samples of the wort increased by 13-57\% compared with the control ones. The concentration of the components of enanthic ether, represented by ethyl caprate, ethyl caprylate, ethyl caproate, increased in the wort samples by $30-120 \%$. It is believed, that these volatile components give specific floral shades to the distillates aroma and harmonize the organoleptic characteristics of alcoholic drinks (Li et al., 2012; Kostik and Memeti, 2013).

It was estimated the effectiveness of a new method of preparing of dried Jerusalem artichoke to distillation on the basis of experimental data by the yield of distillate (average fraction or heart) calculated on anhydrous alcohol when processing $10 \mathrm{~kg}$ of prepared wort. The initial data for the calculation of the fractions yield presented in Table 3. While the strength of fermented wort increased from $7.31 \%$ to $11.15 \%$ (sample 1) and from $7.58 \%$ to $11.48 \%$ (sample 2) revealed a clear tendency to increase the volume of all fractions. The head ranged from 6 to $50 \%$, heart - from 13 to $34 \%$, tail - from 5 to $30 \%$. At the same time, no regularities were revealed for changing the strength of individual fractions. The strength of heart (final distillate) averaged $84-85 \%$ vol., that is, it practically did not depend on the strength of the distilled wort.

Table 3. Baseline Data for Calculating the Yield of Distillate Fractions Depending on the Strength of the Fermented Wort

\begin{tabular}{|c|c|c|c|c|c|c|c|c|c|c|}
\hline Indicator Name & C 1 & S 1.1 & S 1.2 & S 1.3 & S 1.4 & S 2 & S 2.1 & S 2.2 & S 2.3 & S 2.4 \\
\hline $\begin{array}{l}\text { Volume of } \\
\text { from } 10 \quad \mathrm{~kg} \text { of } \\
\text { fermented } \\
\mathrm{cm}^{3}\end{array}$ & 730 & 830 & 925 & 1020 & 1115 & 760 & 860 & 955 & 1050 & 1150 \\
\hline \multicolumn{11}{|l|}{$\begin{array}{l}\text { Fraction volume. } \\
\mathrm{cm}^{3} \text { : }\end{array}$} \\
\hline - head & 75 & 80 & 90 & 110 & 145 & 70 & 75 & 75 & 100 & 135 \\
\hline - heart & 655 & 750 & 850 & 925 & 990 & 690 & 800 & 900 & 970 & 1030 \\
\hline - tail & 850 & 900 & 950 & 1000 & 1210 & 900 & 950 & 950 & 1115 & 1200 \\
\hline \multicolumn{11}{|l|}{$\begin{array}{l}\text { Alcohol volume } \\
\text { proportion in the } \\
\text { fraction. } \% \text { : }\end{array}$} \\
\hline - head & 84.7 & 85.0 & 85.1 & 85.0 & 84.8 & 84.1 & 84.4 & 84.7 & 84.0 & 84.2 \\
\hline - heart & 84.2 & 84.5 & 84.7 & 84.5 & 84.2 & 83.9 & 84.0 & 84.1 & 83.7 & 84.0 \\
\hline - tail & 10.7 & 11.4 & 10.5 & 11.2 & 10.0 & 11.4 & 10.4 & 11.7 & 10.9 & 11.6 \\
\hline Losses of a.a.. \% & 3.3 & 3.0 & 3.1 & 3.2 & 3.3 & 2.6 & 2.9 & 2.4 & 3.1 & 2.8 \\
\hline
\end{tabular}

The data, presented in Table 3 allowed us to calculate the yield of fractions by absolut alcohol (Figures 1, 2).

It was established that with an increase in the strength of the wort by $1-2 \%$, the share of the head fraction decreased by $0.3-1.0 \%$, and a further increase in the strength of the wort (by
$3-4 \%)$ led to an increase in the yield of the head fraction by $0.3-2.3 \%$, depending on the method of Jerusalem artichoke preparation for distillation. The yield of the tail fraction on the contrary was characterized by a tendency to decrease. 


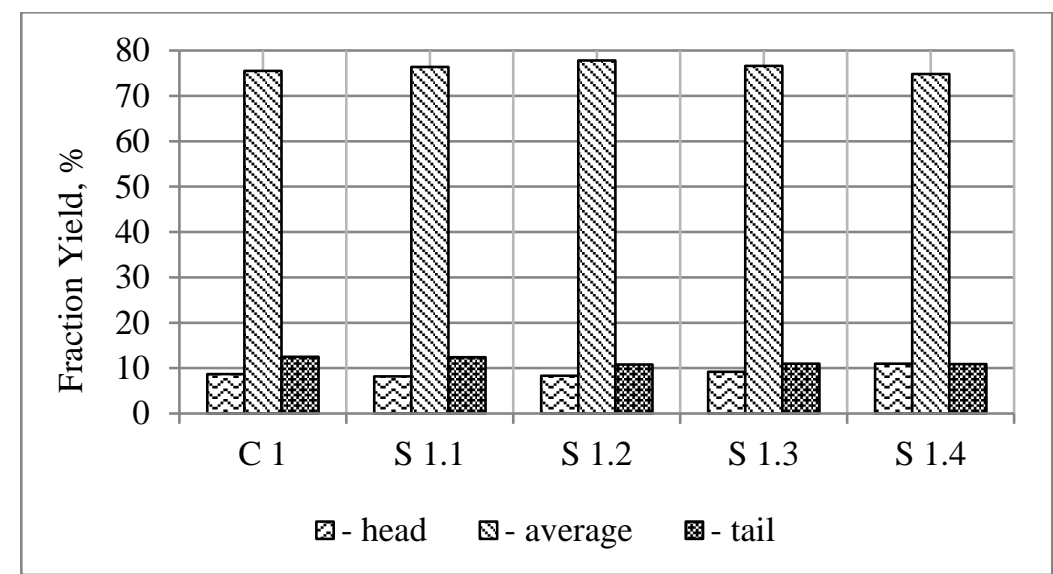

Figure 1. Fractions Yield by Absolut Alcohol during the Wort Samples Distillation, Obtained by the Two-Stage Method (Sample 1)

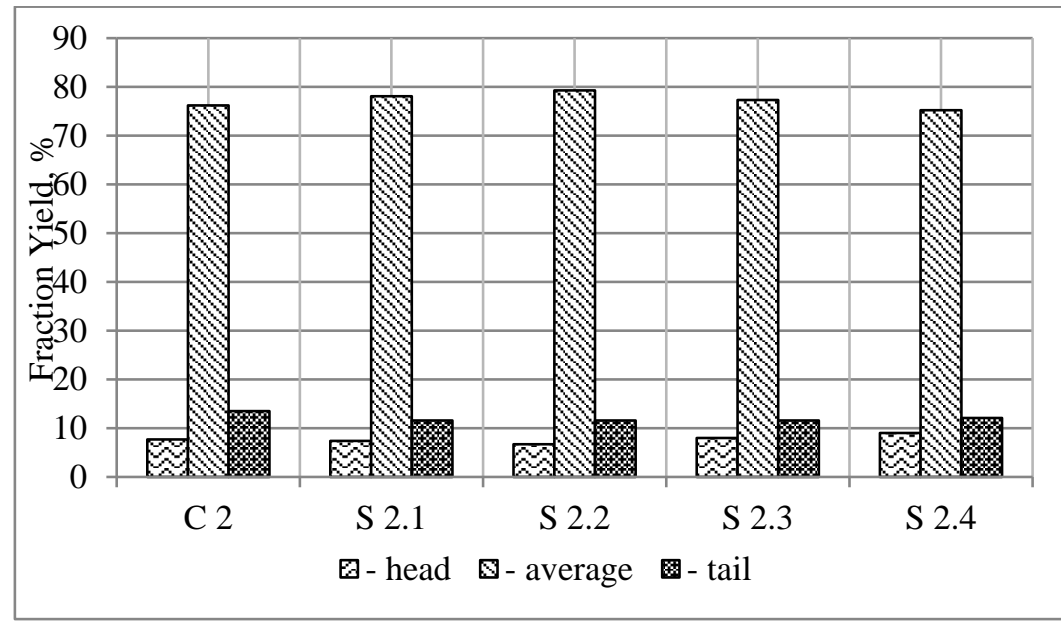

Figure 2. Fractions Yield by Absolut Alcohol during the Wort Samples Distillation, Obtained by the Single-Stage Method (Sample 2)

The data presented in Figures 1 and 2 showed that to achieve the maximum yield of the average fraction (distillate from dried Jerusalem artichoke), increasing the strength of the original wort by adding additional distillate volume, obtained from fractional distillation of previous batches of control samples should be 2-2.5\%. For example, the yield of distillate in test samples $\mathrm{S} 1.2$ and $\mathrm{S}$ 2.2 was maximum compared with the control and increased by 2.8 and $3.1 \%$, respectively.

Distillate-based alcoholic drinks are a special group of elite expensive products. In its production of these spirits, it is necessary to take into account not only the economic aspects, determined by the output of products from a unit of raw materials, but first and foremost consumer properties. In this case, the concept of consumer properties includes safety indicators and organoleptic characteristics of the product. The organoleptic characteristics of distilled drispirits, produced without exposure in contact with the wood of oak or other wood species are determined by the composition of the fragrance forming volatile components.

The study of content of volatile components in experimental samples of distillates have shown that the qualitative composition and quantitative content of volatile components in the distillate prototypes from dried Jerusalem artichoke differed significantly in dependence on the level of increase in the initial strength of the wort. These changes were reflected in the results of organoleptic analysis. As a rule, when distillates and distilled drinks sensory evaluation, tasters use a system of descriptive descriptors and an intensity scale. The choice of descriptors system is a fundamental element 
in preparation for an organoleptic analysis and includes a descriptive characteristic of appearance (color, transparency, the presence of sediment), flavor, its shades and taste (Brochet, Dobourdieu, 2001).

To characterize a new type of product (distillates from dried Jerusalem artichoke), we used certain descriptors for flavor and taste evaluation.

The following descriptors were used to evaluate the flavor: intensity: bright, strong, moderate, weak; character: peculiar to initial raw materials, fruit, flower and honey, including undesirable - fusel, alcohol, musty, sharp; shades: enanthic, grassy, including

indicators. The main differences between the samples were identified by the nature and intensity of aroma and taste (Table 4). undesirable - salty, boiled down, medicinal, oxidized.

The following descriptors were used to evaluate the taste: character: soft, refined, oily, including undesirable - sugary, pungent, sharp, rough; harmony: harmonious, inharmonious, disorganized; typicality: typical, atypical, with a foreign tint.

Color and transparency were estimated in the range of 1-2 points. The aroma and taste were estimated in the range of 1-3 points.

According to the results of the organoleptic analysis of distillates from dried Jerusalem artichoke, all samples (control and experimental) were colorless and transparent and received the highest rating for these.

Table 4. Organoleptic Analysis of Dried Jerusalem Artichoke Distillates Samples

\begin{tabular}{|l|c|c|c|c|c|}
\hline Sample & $\begin{array}{c}\text { Colour } \\
(\mathbf{m a x} 2 \mathbf{p t s})\end{array}$ & $\begin{array}{c}\text { Clearness } \\
(\mathbf{m a x} 2 \mathbf{p t s})\end{array}$ & $\begin{array}{c}\text { Odor } \\
(\mathbf{m a x} \text { 3 pts })\end{array}$ & $\begin{array}{c}\text { Taste } \\
(\mathbf{m a x} \text { 3 pts })\end{array}$ & $\begin{array}{c}\text { Total } \\
(\mathbf{m a x} \text { 10 pts })\end{array}$ \\
\hline C1 & 2 & 2 & 2.6 & 2.5 & 9.1 \\
\hline S 1.1 & 2 & 2 & 2.7 & 2.6 & 9.3 \\
\hline S 1.2 & 2 & 2 & 2.9 & 2.8 & 9.7 \\
\hline S 1.3 & 2 & 2 & 2.9 & 2.8 & 9.7 \\
\hline S 1.4 & 2 & 2 & 2.7 & 2.7 & 9.4 \\
\hline C 2 & 2 & 2 & 2.7 & 2.5 & 9.2 \\
\hline S 2.1 & 2 & 2 & 2.9 & 2.7 & 9.6 \\
\hline S 2.2 & 2 & 2 & 3.0 & 2.8 & 9.8 \\
\hline S 2.3 & 2 & 2 & 3.0 & 2.8 & 9.8 \\
\hline S 2.4 & 2 & 2 & 2.8 & 2.8 & 9.6 \\
\hline
\end{tabular}

The results processing of the organoleptic analysis using selected descriptors was carried out graphically, which is widely used in the statistical processing of the organoleptic evaluation of various types of food products. Figures 3 and 4 show the aromatic and taste profiles of distillates from dried Jerusalem artichoke (sample 1 - preparation of the wort in a two-stage process).In the study of the distillate aromatic profiles revealed significant differences between the samples according to the nature and intensity of the aroma.

Unlike the control sample (C 1), which had a weak, unexpressed flavor, the best prototypes (S 1.2 and S 1.3) were characterized by a pronounced aroma of raw materials with bright floral-honey and fruit shades. It was noted that the sample (S 1.4) with the maximum addition of distillate into the wort, was distinguished by a sharp aroma with a strong fuss shade.Analysis of the taste profiles of distillates from dried Jerusalem artichoke made it possible to establish that the control sample (C 1) had an inexpressive taste. The introduction of a certain volume of distillate into the wort (an increase in strength by an average of $2.0 \%$ vol.) resulted a product characterized by a pronounced, soft, harmonious, typical taste with oily tints. A further increase in the volume of distillate, introduced into the wort led to the appearance of coarse and sharp tones in the taste of the distillate (S 1.4). 


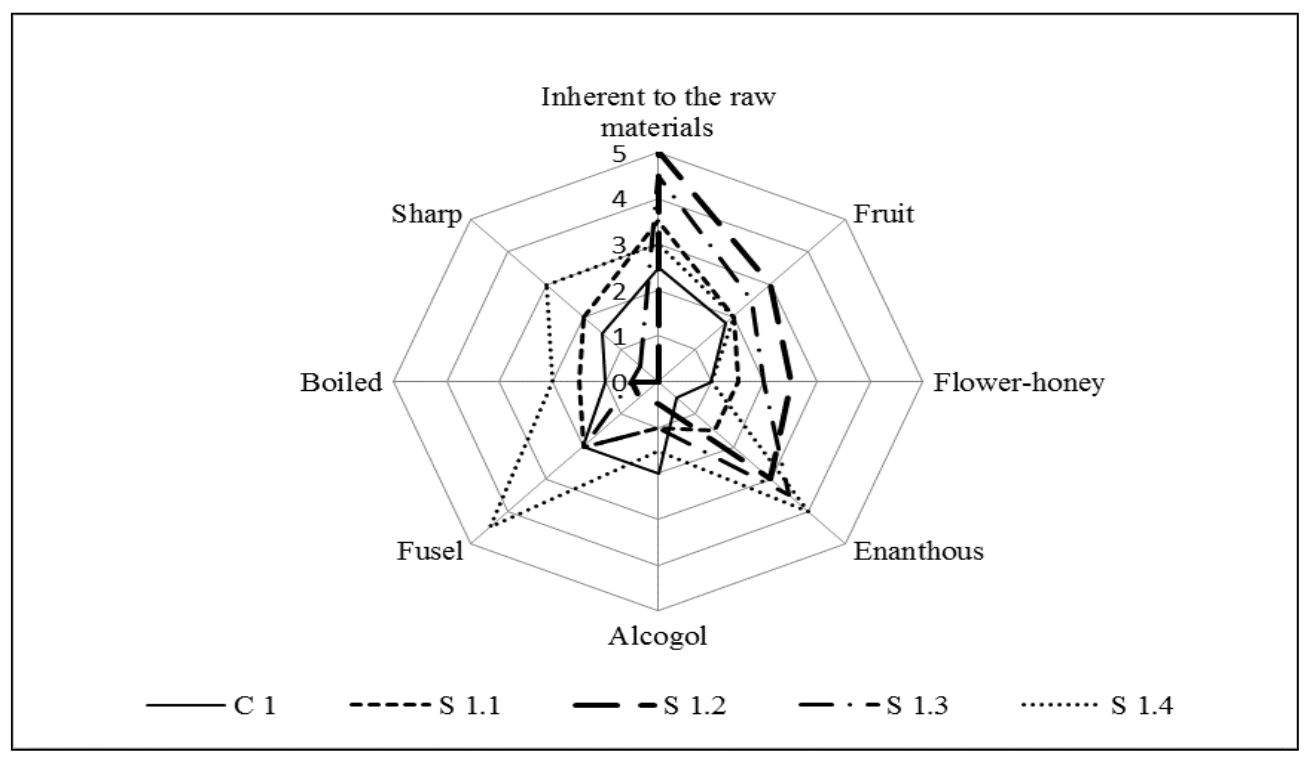

Figure 3. Distillate Aromatic Profiles from Dried Jerusalem Artichoke

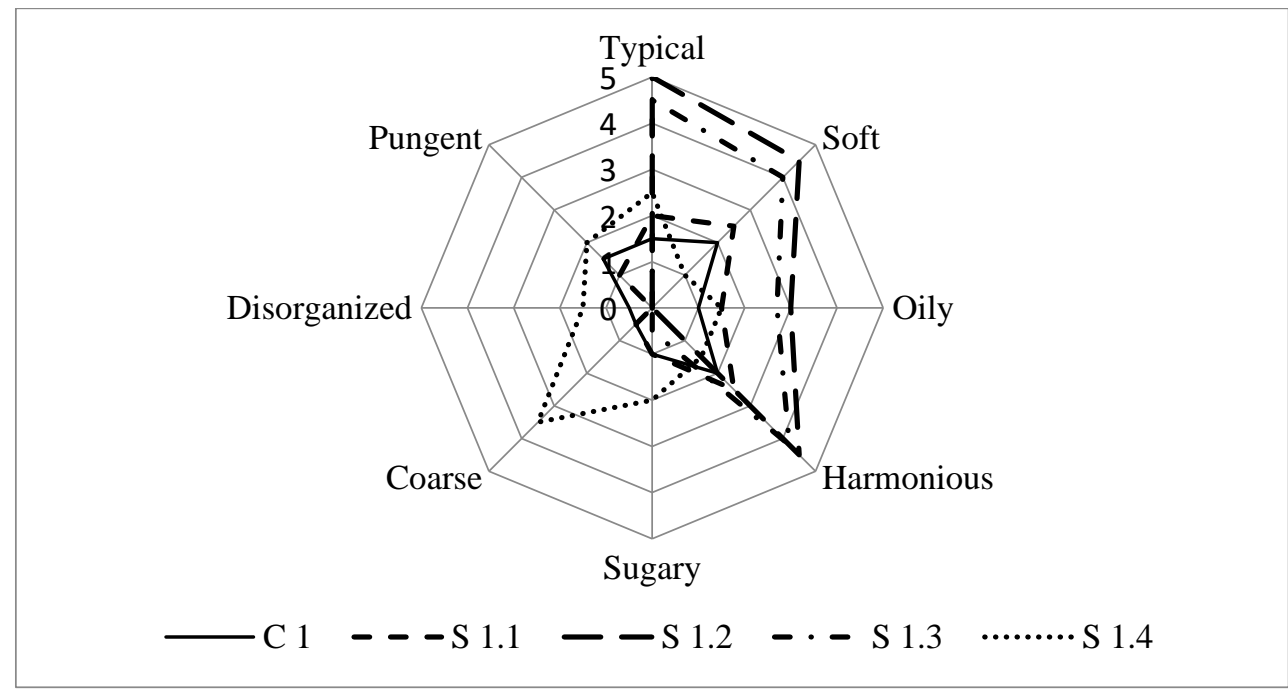

Figure 4. Distillate Taste Profiles from Dried Jerusalem Artichoke

For a deeper understanding of the volatile component influence degree on the taste and aromatic characteristics of distillates, we calculated the pair correlation coefficients between the concentration of individual volatile components, as well as the ratios of individual groups of components, and the tasting assessment (Table 5).

According to the data obtained, the composition of the volatile components of all distillate samples from dried Jerusalem artichoke was dominated by higher alcohols, which accounted for $62-69 \%$ of the total amount of volatile components. From aliphatic higher alcohols in the control and experiment samples of distillates 1-propanol, 2-propanol, isobutanol, 1-butanol, isoamylol, hexanol were identified. Despite the high content of this group of volatile components, no significant correlation was found between their total concentration and tasting assessment. Isobutanol and isoamylol, which are the main components of fusel oils, were contained in the studied samples in concentrations from 598 to $1100 \mathrm{mg} / \mathrm{dm}^{3}$ a.a. and from 1300 to $2459 \mathrm{mg} / \mathrm{dm}^{3}$ a.a, respectively, which significantly exceeded their threshold concentrations in aroma perception (Arrieta-Garay et al., 2014). However, it was found that the coefficients of 
pair correlation of these components with the organoleptic evaluation of distillates had low values (0.115 and 0.087$)$, respectively.

The detected concentrations of hexanol turned out to be significantly lower than the threshold ones, while the pair-correlation coefficient for this substance had a numerically significant negative value, well above the critical value. The concentration of 1-propanol with a pleasant, oily-floral aroma ranged from 532 to $821 \mathrm{mg} / \mathrm{dm}^{3}$ a.a. The threshold perception of 1-propanol is at the level of $100-500 \mathrm{mg} / \mathrm{dm}^{3}$. The high value of 1 propanol was llowed us to make a conclusion about its positive effect on the formation and character of the aroma of distillates from dried Jerusalem artichoke. Also, the data, presented in Table 5 showed that the ratio of $\mathrm{C}_{3}$ and $\mathrm{C}_{4}$ alcohols is significant for evaluation of character of flavor and taste.

Phenylethyl alcohol was found in insignificant amounts. Given that the threshold perception of it is in the range from $10 \mathrm{mg} / \mathrm{dm}^{3}$ to $80 \mathrm{mg} / \mathrm{dm}^{3}$, and the value of the $\mathrm{r}_{\mathrm{xy}}$ for it was 0.011 , it can be argued that this component does not affect on the flavor of the distillate from dried Jerusalem artichoke.

Table 5. The Relationship of the Volatile Components Qualitative and Quantitative Composition and the Tasting Evaluation of Jerusalem artichoke Distillates

\begin{tabular}{|c|c|c|c|c|c|c|c|c|c|c|c|}
\hline \multirow{2}{*}{ Indicator } & \multicolumn{10}{|c|}{ Volatile Components, $\mathrm{mg} / \mathrm{dm}^{3}$ of a.a. } & \multirow{2}{*}{$\mathbf{r}_{\mathrm{xy}}$} \\
\hline & $\mathrm{C} 1$ & S 1.1 & S 1.2 & $\mathrm{~S} 1.3$ & S 1.4 & $\mathrm{C} 2$ & S 2.1 & S 2.2 & S 2.3 & S 2.4 & \\
\hline Ethanol, \% v/v & 84.2 & 84.5 & 84.7 & 84.5 & 84.2 & 83.9 & 84.0 & 84.1 & 83.7 & 84.0 & \\
\hline Methanol & 1407 & 1496 & 1536 & 1587 & 1970 & 1050 & 1241 & 1302 & 1421 & 1802 & -0.074 \\
\hline Acetaldehyde & 214 & 202 & 186 & 187 & 204 & 143 & 130 & 120 & 118 & 115 & -0.584 \\
\hline Isobutyraldehyde & 2 & 2 & 1 & 1 & 2 & 1 & 0 & 0 & 1 & 1 & -0.670 \\
\hline Acetone & 7 & 8 & 5 & 5 & 6 & 6 & 5 & 4 & 4 & 6 & -0.872 \\
\hline 2-propanol & 5 & 4 & 2 & 3 & 4 & 4 & 4 & 2 & 2 & 3 & -0.941 \\
\hline 1-propanol & 544 & 659 & 796 & 821 & 705 & 532 & 609 & 725 & 751 & 740 & 0.728 \\
\hline Isobutanol & 706 & 826 & 853 & 904 & 1100 & 598 & 710 & 765 & 832 & 904 & 0.115 \\
\hline 1-butanol & 24 & 19 & 13 & 15 & 25 & 23 & 18 & 10 & 13 & 19 & -0.935 \\
\hline Isoamilol & 1552 & 1800 & 1939 & 2058 & 2459 & 1300 & 1461 & 1611 & 1800 & 1987 & 0.087 \\
\hline Hexanol & 16 & 14 & 8 & 10 & 13 & 14 & 10 & 5 & 7 & 10 & -0.967 \\
\hline $\begin{array}{l}\text { Phenylethyl } \\
\text { alcohol }\end{array}$ & 8 & 8 & 7 & 7 & 7 & 9 & 8 & 9 & 8 & 8 & 0.011 \\
\hline Isoamylacetate & 5 & 6 & 8 & 10 & 9 & 7 & 9 & 11 & 12 & 7 & 0.862 \\
\hline Ethyl acetate & 68 & 64 & 64 & 75 & 98 & 70 & 70 & 70 & 89 & 109 & 0.059 \\
\hline Ethylcaproate & 13 & 14 & 15 & 15 & 12 & 14 & 14 & 15 & 15 & 14 & 0.807 \\
\hline Ethyl lactate & 4 & 3 & 1 & 1 & 2 & 3 & 3 & 2 & 1 & 2 & -0.801 \\
\hline Ethyl caprylate & 11 & 12 & 16 & 15 & 14 & 13 & 14 & 17 & 17 & 15 & 0.952 \\
\hline Ethylcaprate & 24 & 29 & 41 & 48 & 61 & 28 & 41 & 49 & 70 & 81 & 0.492 \\
\hline $\begin{array}{l}\text { Aldehydes and } \\
\text { ketones }\end{array}$ & 223 & 212 & 192 & 193 & 212 & 150 & 135 & 124 & 123 & 122 & -0.603 \\
\hline Higher alcohols & 2847 & 3322 & 3611 & 3811 & 4306 & 2471 & 2812 & 3118 & 3405 & 3663 & 0.199 \\
\hline Ethers & 125 & 128 & 145 & 164 & 196 & 135 & 151 & 164 & 204 & 228 & 0.401 \\
\hline $\begin{array}{l}\text { Enanthic ethers } \\
\text { sum }\end{array}$ & 48 & 55 & 72 & 78 & 87 & 55 & 69 & 81 & 102 & 110 & 0.588 \\
\hline $\begin{array}{l}\text { The ratio of } \\
\text { alcohols } C_{5} \text { to the } \\
\text { sum of } C_{3}, C_{4}\end{array}$ & 1.24 & 1.21 & 1.18 & 1.19 & 1.36 & 1.15 & 1.10 & 1.08 & 1.13 & 1.21 & -0.604 \\
\hline $\begin{array}{l}\text { The ratio of } \\
\text { alcohols } C_{3} / C_{4}\end{array}$ & 0.77 & 0.80 & 0.93 & 0.91 & 0.64 & 0.89 & 0.86 & 0.95 & 0,90 & 0.82 & 0.717 \\
\hline $\begin{array}{l}\Sigma \text { of enanthic } \\
\text { ethers / ethyl } \\
\text { acetate }\end{array}$ & 0.71 & 0.86 & 1.12 & 1.04 & 0.89 & 0.79 & 0.99 & 1.16 & 1.14 & 1.00 & 0.966 \\
\hline $\begin{array}{l}\text { Tasting } \\
\text { evaluation, score }\end{array}$ & 7.4 & 7.5 & 7.7 & 7.7 & 7.5 & 7.5 & 7.6 & 7.8 & 7.8 & 7.6 & \\
\hline
\end{tabular}


The ethers in the studied samples were represented by ethyl acetate, isoamyl acetate, ethyl caproate, ethyl lactate, ethyl caprylate, ethyl caprate. Ethyl acetate, whose threshold concentration ranged from 50 to $100 \mathrm{mg} / \mathrm{dm}^{3}$ was found in the largest quantities in studied distillates. It has been established that there is practically no correlation between the concentration of ethyl acetate and the tasting assessment $(\mathrm{r}=0.059)$. The mass concentration of enant ethers (ethylcaproate, ethylcaprylate, ethylcaprate) significantly exceeded their threshold concentrations. The values of $r_{x y}$ for ethylcaproate and ethylcaprylate were close to 1.0 , which indicates their significant role in formation the distillates aroma. A high positive correlation was noted between the tasting evaluation and the ratio of the sum enanthic ethers and ethyl acetate $(r=0.966)$.

The concentration of isoamylacetate, which in its pure form has a sharp, fruity smell like pears, in the studied samples ranged from 5 to $12 \mathrm{mg} / \mathrm{dm}^{3}$ a.a. The correlation coefficient for isoamyl acetate was 0.862 , which, taking into account the threshold concentration of this component $\left(0.5-5.0 \mathrm{mg} / \mathrm{dm}^{3}\right)$, indicates its importance in the perception of the distillates aroma from Jerusalem artichoke.

Of the carbonyl compounds (aldehydes and ketones) in the studied samples, acetaldehyde was the main (in concentrations exceeding the threshold by 1.5-2 times). Isobutyraldehyde was presented in trace concentrations. All carbonyl compounds had high negative correlation coefficients with a tasting score.

The concentration of methanol in distillates from dried Jerusalem artichoke varied from 1050 to $1970 \mathrm{mg} / \mathrm{dm}^{3}$ a.a. The dependence of the increase in methanol concentration on the level of increase in the strength of fermented wort was revealed. The absolute values of this indicator in samples of distillates from dried Jerusalem artichoke did not exceed the permissible maximum content of methanol in distillates $\left(2 \mathrm{~g} / \mathrm{dm}^{3}\right)$ established in the Russian Federation. According to the results of the correlation analysis, it was concluded that methanol in the indicated concentrations had no effect on the organoleptic characteristics of the distillates obtained $(\mathrm{r}=-0.074)$.

In general, the obtained results allowed us to single out a number of individual components and groups of compounds that, to one degree or another, influence the character of the aroma and the taste perception of distillates from dried Jerusalem artichoke. On the basis of the obtained results, we recommended the following criteria for assessing the quality of distillates from dried Jerusalem artichoke: the total concentration of methanol should not exceed $1.6 \mathrm{~g} / \mathrm{dm}^{3}$ a.a., enanthic ethers should be at least $70 \mathrm{mg} / \mathrm{dm}^{3}$ a.a., the total content of carbonyl compounds should not exceed $200 \mathrm{mg} / \mathrm{dm}^{3}$ a.a., the ratio of the sum of enanthic ethers to the concentration of ethyl acetate should be at least 1.1.

\section{Conclusions}

Revealed regularities of changes in the concentrations of the main volatile components of the distillate from dried Jerusalem artichoke depending on the strength of the fermented wort and its composition. It is shown that an increase in the strength of fermented wort is on average $2 \%$ vol. leads to an increase in the yield of distillate and its enrichment with valuable volatile components (higher alcohols and enanthic ethers).

A high degree of correlation was established between the tasting evaluation of distillates from dried Jerusalem artichoke and the concentration of individual volatile components, groups of compounds and their ratios: positive for 1-propanol, ethyl caproate, ethyl caprylate, amounts of enanthic ethers, ratios of $\mathrm{C}_{3}$ and $\mathrm{C}_{4}$ alcohols, ratio of the amount of enanthic ethers to ethyl acetate; negative for acetaldehyde, isobutyraldehyde, the sum of aldehydes and ketones, ethyl lactate, the ratio of alcohols $\mathrm{C}_{5}$ to the sum of alcohols $\mathrm{C}_{3}, \mathrm{C}_{4}$.

A new distillate technology from dried Jerusalem artichoke has been developed, based on the regulation of strength and composition of fermented wort, which allows to increase the efficiency of the process. 


\section{References}

Arrieta-Garay, Y., Blanco, P., LópezVázquez, C., Rodríguez-Bencomo, J.J., Perez-Correa, J.R., Lopez, F., Orriols, I. (2014). Effects of Distillation System and Yeast Strain on the Aroma Profile of Albariño (Vitis vinifera L.) Grape Pomace Spirits. Journal of Agricultural and Food Chemistry, 62(43), 10552-10560.

Baranenko, D.A., Borisova, I.I. (2014). The Substantiation of the Production Technological Parameters of Stable Functional Ingredients from Jerusalem Artichoke during Storage. Scientific Journal NRU ITMO. Series "Food Production Processes and Devices", 4, 1320.

Barkhatova, T. V., Nazarenko, M. N., Kozhukhova, M. A., Khripko, I. A. (2015). Obtaining and Identification of Inulin from Jerusalem Artichoke (Helianthus tuberosus) Tubers. Foods and Raw Materials, 3(2), 13-22. DOI: $10.12737 / 13115$.

Bekers, M. Grube M., Upite, D., Kaminska, E., Danilevich, A., Viesturs, U., Karklina, D. (2008). Inulin Syrup from Dried Jerusalem Artichoke. LLU Raksti, 21 (315), 116-121.

Borovikov, V.P. (2003). Statistica. The Art of Analyzing Data on a Computer for Professionals. St. Petesburg: Piter, pp. 105-146.

Brochet, F., Dobourdieu, D. (2001). Wine Descriptive Language Supports Cognitive Specificity of Chemical Senses, Brain and Language, 77, 187-196.

Claus, M.J., Berglund, K.A. (2005). Fruit Brandy Production by Batch Column Distillation with Reflux. Journal of Food Process Engineering, 28, 53-67. DOI: 10.1111/j.1745-4530.2005.00377.x

Dürr, P., Albrecht, W., Gössinger, M., Hagmann, K., Pulver, D., Scholten, G. (2010). Technologie der Obstbrennerei. Eugen Ulmer K G, pp. 126-210.

Grachev, Yu.P., Plaksin, Yu.M. (2005). Mathematical Methods for Experiment Planning. Moscow: Publishing House Deli print, 80.

Ilchenko, S.M., Patlasov, O.Yu. (2016). Jerusalem Artichoke and its Processing
Products Market Situation. Omsk State Agrarian University Bulletin, 21(1), 261266.

Khripko, I.A., Kozhukhova, M.A. (2003). Changes in the Jerusalem Artichoke Carbohydrate Complex during Freezing and Storage. News of Universities. Food Technology, 4, 72-74.

Kostik, V., Memeti, S., Bauer, B. (2013). GasChromatographic Analysis of Some Volatile Congeners in Different Types of Strong Alcoholic Fruit Spirits. Journal of Hygienic Engineering and Design, 4, 98102.

Krikunova, L.N., Peschanskaya, V.A., Obodeeva, O.N., Zakharov, M.A. (2016). The Study of Dried Jerusalem Artichoke Biochemical Composition. Storage and Processing of Agricultural Raw Materials, 8, 29-33.

Krikunova, L.N., Peschanskaya, V.A., Dubinina, E.V. (2017). Some Aspects of the Jerusalem Artichoke Tubers Distillate Production (Part 1. Distribution Dynamics of Fermented Wort Volatile Components during Distillation). Technique and Technology of Food Production, 1, 17-23.

Li, H., Wang, C., Zhu, L., Huang, W., Yi, B., Zhang, L., Shen, C., Zhang, S., Xu, D. (2012). Variations of Flavor Substances in Distillation Process of Chinese LizhouFlavor Liquor. Journal of Food Process Engineering, 35, 314-319.

Lisovoy, V.V., Viktorova, E.P., Shakhray, T.A. (2016). Initial Requirements Development for the Production Technology of Jerusalem artichoke Inulin. Technologies of Food and Processing Industry of the Agroindustrial Complex Healthy Food Products, 2, 43-48.

Nakamura, T., Ogata, Y., Hamada, S., Ohta, K. (1996). Ethanol Production from Jerusalem Artichoke Tubers by Aspergillus niger and Saccharomyces cerevisiae. Journal of Fermentation and Bioengineering, 81(6), 564-566. DOI: 10.1016/0922-338X(96)81482-6

Oganesyants, L.A., Peschanskaya, V.A., Krikunova, L.N., Obodeeva, O.N. (2016). Technology Development for Distilled Alcohol Drinks from Jerusalem Artichoke 
(Part 1. Stage of Saccharified Wort Production). Beer and Drinks, 6, 34-37.

Oganesyants, L.A., Peschanskaya, V.A., Krikunova, L.N., Obodeeva, O.N. (2017). Technology Development for Distilled Alcohol Drinks from Jerusalem Artichoke (Part 2. Sugared Wort Fermentation Stage). Beer and Drinks, 1, 26-29.

Ponomareva, M.S., Krikunova, L.N., Gernet, M.V. (2009). Jerusalem Artichoke Processing Complex Technology in Alcohol Industry Part I. Production of Alcohol and Alcoholic Drinks, 1, 22-25.

Pornthap Thanonkeo, Sudarat Thanonkeo, Kannikar Charoensuk, Mamoru Yamada. (2011). Ethanol production from Jerusalem artichoke (Helianthus tuberosus L.) by Zymomonas mobilis TISTR548. African Journal of Biotechnology, 52 (10), 10691-10697.

Prado-Ramirez, R., Gonzáles-Alvarez, V., Pelayo-Ortiz, C., Casillas, N., Estarrón, M., Gómez-Hernández, H.E. (2005). The Role of Distillation on the Quality of Tequila. International Journal of Food Science and Technology, 40(7), 701-708. DOI: $10.1111 / \mathrm{j} .1365-2621.2005 .00983 . \mathrm{x}$

DOI: 10.1111/j.1365-2621.2005.00983.x

Shazzo, R.I., Zayko, G.M., Kurguzova, K.S., Kornen, N.N., Chernenko, A.V., Tamazova, S.Yu. (2013). Food Functional Product. Patent A23L 1/212 RU 2541385. State Standard 33834 (2016). Wine-Making Products and Raw Materials for its Production. Gas Chromatographic Method for Determining the Volatile Components Mass Concentration. Introdused 2018-0101. Moscow: Standartinform, 11.

Toshkov, N., Delchev, N., Kozludzhova, S. (2015). Sorption characteristics of pectin isolated from Jerusalem Artichoke tubers (Helianthus tuberosus L.). Ukrainian Food Journal, 3(2), 185-192.

Yakovleva, Yu.A., Arsen'eva, T.P. (2012). Ice Cream Formulation with Herbal Ingredients. News of Universities "Food Technology", 1, 73-75.

\section{Acknowledgement}

The authors are grateful to Russian Academy of Sciences, Government of the
Russian Federation for the financial support to conduct this research work. 